\title{
Preference of Sweetpotato Whitefly Adults to Cucumber Seedlings Grown under Two Different Light Sources
}

\author{
Toshio Shibuya ${ }^{1}$, Junki Komuro, Norio Hirai, Yoshiko Sakamoto, \\ Ryosuke Endo, and Yoshiaki Kitaya
}

ADDITIONAL INDEX wORDs. fluorescent lamp, red:far red, R:FR, transplant production

SummaRY. We evaluated the preference of adult sweetpotato whitefly [SPWF (Bemisia tabaci biotype B)] to cucumber (Cucumis sativus) seedlings grown under fluorescent lamps (FLs) or metal-halide lamps (MLs) that provided a spectrum similar to that of natural light. Cucumber seedlings were grown under FLs or MLs at a photosynthetic photon flux of $350 \mu \mathrm{mol} \cdot \mathrm{m}^{-2} \cdot \mathrm{s}^{-1}$ in a $12 / 12$-hour light/dark cycle. The red:far red (R:FR) ratio of FL was 7.0 and that of ML was 1.2. Pairs of cucumber seedlings, one grown under FLs and the other under MLs, were then placed in cages and about 100 SPWF adults were released. There were significantly fewer SPWF adults on the FL cucumber seedlings (36\%) than on the ML seedlings (64\%) 24 hours after release. FL cucumber seedlings had higher chlorophyll content and thicker leaves than ML seedlings. The lower attractiveness of the FL cucumber seedlings was probably due to changes in morphologic characteristics such as the leaf color and thickness resulting from high R:FR illumination of FL. The fact that light quality affects the plant attractiveness to herbivores should be considered in selecting light sources for transplant production under artificial light.

$\mathrm{H}$ igh-performance transplant production systems using artificial light have been developed as a way to produce high-quality transplants regardless of the weather (Kozai, 2007; Kozai et al., 2006). The plants grown under the fluorescent lamps used in these systems have shorter shoots than those grown under natural light (Ohyama et al., 2003). The reduced shoot elongation is due to the high R:FR ratio of typical commercial FLs, which emit little FR irradiation. Thus, increasing the FR content of the light from these lamps can improve the elongation of plant shoots (Murakami et al., 1991; Shibuya et al., 2010). In natural environments, a reduction in the R:FR ratio resulting from the absorption of red light by neighboring vegetation increases shoot elongation and leaf expansion and reduces leaf thickness and chlorophyll content (Franklin, 2008; Smith and Whitelam, 1997). This morphologic response is called shade avoidance and reduces plant

Graduate School of Life and Environmental Science, Osaka Prefecture University, Gakuen-cho, Naka-ku, Sakai, Osaka 599-8531, Japan

This study was supported by the Japan Society for the Promotion of Science (Grant-in-Aid for Challenging Exploratory Research, 20658059, 2008-2009).

${ }^{1}$ Corresponding author. E-mail: shibuya@envi.osakafuu.ac.jp. resistance to herbivores (Ballaré, 2009; Izaguirre et al., 2006; McGuire and Agrawal, 2005; Moreno et al., 2009). Environmental factors often have indirect effects on herbivore behavior through their effects on the morphologic, physiologic, and chemical characteristics of plants (Berlinger, 1986; Chu et al., 1999; McAuslane, 1996; Shibuya et al., 2009; Waring and Cobb, 1992). Therefore, illumination by FLs with higher-thannatural $\mathrm{R}: \mathrm{FR}$ ratio may reduce the attractiveness of plants to herbivores. If FLs can make transplants less attractive to herbivores, they may be able to reduce both pest numbers and the use of pesticides at transplanting. To test this hypothesis, we evaluated the preference of adult SPWF (Bemisia tabaci biotype $\mathrm{B}$ ) to cucumber (Cucumis sativus) seedlings grown under commercial FLs or under MLs that provided a spectrum similar to that of natural light.

\section{Materials and methods}

'Hokushin' cucumber seeds were sown in plastic pots $(60 \mathrm{~mm}$ diameter, $55 \mathrm{~mm}$ tall) containing vermiculite. The cucumber seedlings were grown in a growth chamber maintained at $28{ }^{\circ} \mathrm{C}$ and a relative humidity of $50 \%$ at a photosynthetic photon flux $(P P F)$ of $300 \mu \mathrm{mol} \cdot \mathrm{m}^{-2} \cdot \mathrm{s}^{-1}$ provided by FLs (FHF32EX-N-H; Panasonic, Kadoma, Japan) in a $12 / 12$-h light/dark cycle. After the cotyledons had fully expanded, the cucumber seedlings were randomly allocated to growth chambers illuminated with FLs (FPL55EX$\mathrm{N}$; Panasonic) or with MLs (DR400/ TL; Toshiba Lighting and Technology, Yokosuka, Japan). The $\mathrm{R}$ (wavelength $600-700 \mathrm{~nm})$ to FR $(700-800 \mathrm{~nm})$ ratio of FL was 7.0 and that of ML was 1.2. The spectrum of ML was similar to that of natural light, except that ML had strong peaks at $540-570 \mathrm{~nm}$ (Fig. 1). The spectra were measured using a spectrometer (BLK-CXR-SR; StellarNet, Tampa, FL). The growth conditions for all the chambers were the same as above, except that the PPF was $350 \mu \mathrm{mol} \cdot \mathrm{m}^{-2} \cdot \mathrm{s}^{-1}$ at the first foliage leaves. To maintain the $P P F$ at leaf surface, the distance between the light sources and the leaves was maintained during the growing period by lowering the cucumber seedlings using a jack. The pots were placed in nutrient solution (A-type recipe of Otsuka House Solution; Otsuka Chemical, Osaka, Japan) 5-10 mm deep. The composition of the solution (in grams per 1000 L of tap water) was 260 total nitrogen, 52 phosphorus, 336 potassium, 164 calcium, 36 magnesium, 1.2 manganese, 0.5 boron, 2.7 iron, 0.03 copper, 0.09 zinc, and 0.03 molybdenum. Electrical conductivity was about $2.6 \mathrm{mS} \cdot \mathrm{cm}^{-1}$, and the $\mathrm{pH}$ was about 6.5 throughout the duration of the experiment.

After the first foliage leaf had fully expanded ( 7 and $5 \mathrm{~d}$ after the cotyledons had fully expanded in FL and ML, respectively), pairs of cucumber seedlings from each treatment group

\begin{tabular}{llll}
\hline $\begin{array}{l}\text { Units } \\
\text { To convert U.S. to SI, } \\
\text { multiply by }\end{array}$ & U.S. unit & SI unit & $\begin{array}{l}\text { To convert SI to U.S., } \\
\text { multiply by }\end{array}$ \\
\hline 25.4 & inch $(\mathrm{es})$ & $\mathrm{mm}$ & 0.0394 \\
0.2276 & inch $^{2} / \mathrm{oz}$ & $\mathrm{cm}^{2} \cdot \mathrm{g}^{-1}$ & 4.3942 \\
1 & $\mathrm{mmho} / \mathrm{cm}$ & $\mathrm{mS} \cdot \mathrm{cm}^{-1}$ & 1 \\
1 & $\mathrm{ppm}$ & $\mathrm{g} / 1000 \mathrm{~L}$ & 1 \\
$\left({ }^{\circ} \mathrm{F}-32\right) \div 1.8$ & ${ }^{\circ} \mathrm{F}$ & ${ }^{\circ} \mathrm{C}$ & $\left(1.8 \times{ }^{\circ} \mathrm{C}\right)+32$
\end{tabular}


were placed in four cages $(150 \mathrm{~mm}$ long $\times 300 \mathrm{~mm}$ deep $\times 200 \mathrm{~mm}$ tall; Itagaki-seisakusho, Tokyo) for the preference tests and set in the FL growth chamber. We carried out the preference tests under FLs, because line light sources such as FL are probably suitable for uniform illumination compared with point light sources such as ML. The inside of FL chamber was horizontally symmetric except the side door (Fig. 2). The cages were made of transparent polyvinyl chloride panels with gauze side windows for air flow. Because plants developed faster under MLs than under FLs, FL cucumber seedlings took $2 \mathrm{~d}$ longer to equal the growth stage of ML seedlings. We could obtain pairs of almost equal size plants at the start of the tests by delaying the sowing in ML for $2 \mathrm{~d}$. All leaves except the first foliage leaf were removed. The cucumber seedlings were transplanted into larger plastic pots (105 mm diameter, $90 \mathrm{~mm}$ tall) containing vermiculite before installing them in the cages. The hypocotyls of ML cucumber seedlings were buried deeper to minimize the difference in distance from the surface of the growing medium to the leaves because shoot length in ML was significantly greater than that in FL. Between 90 and 110 SPWF adults were collected into glass test tubes and then released into each cage. The cucumber seedlings were arranged alternatively (Fig. 2 ), and the cages were closed after insect release. We counted the SPWF adults on each cucumber seedling $24 \mathrm{~h}$ after release. The total population of the four cages was used as one trial because of positional effects between door side and non-door side. We performed the preference test three times. The significance of differences in the proportions of SPWF adults between treatments in each trial and their means were determined on the assumption of a normal distribution and the null hypothesis of a $50 \%$ split in proportions (Shibuya et al., 2009).

Ten cucumber seedlings were grown under FLs and MLs following the same method previously described to measure morphologic impacts of the light source. The relative chlorophyll content was evaluated with a chlorophyll meter (SPAD-502; Konica Minolta Sensing, Sakai, Japan). We measured leaf dry weight (DW), leaf area, and shoot length of cucumber seedlings. The specific leaf area was

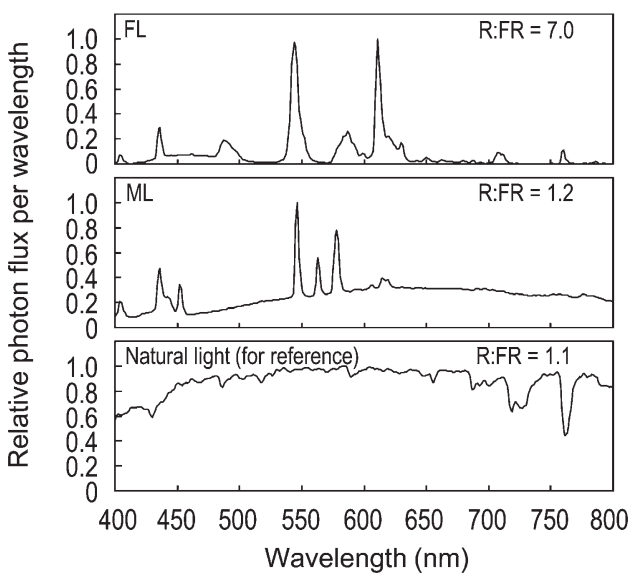

Fig. 1. Spectra of the fluorescent lamp (FL) and metal-halide lamp (ML) similar to the spectrum of natural light, used in the experiments. Relative photon fluxes per unit wavelength are expressed in values relative to the maximum. The red:far red (R:FR) ratio was estimated by dividing the accumulated photon flux from $\mathrm{R}$ light (wavelength 600-700 $\mathrm{nm}$ ) by that from FR light $(700-800 \mathrm{~nm})$. The spectrum of natural light is shown for reference.
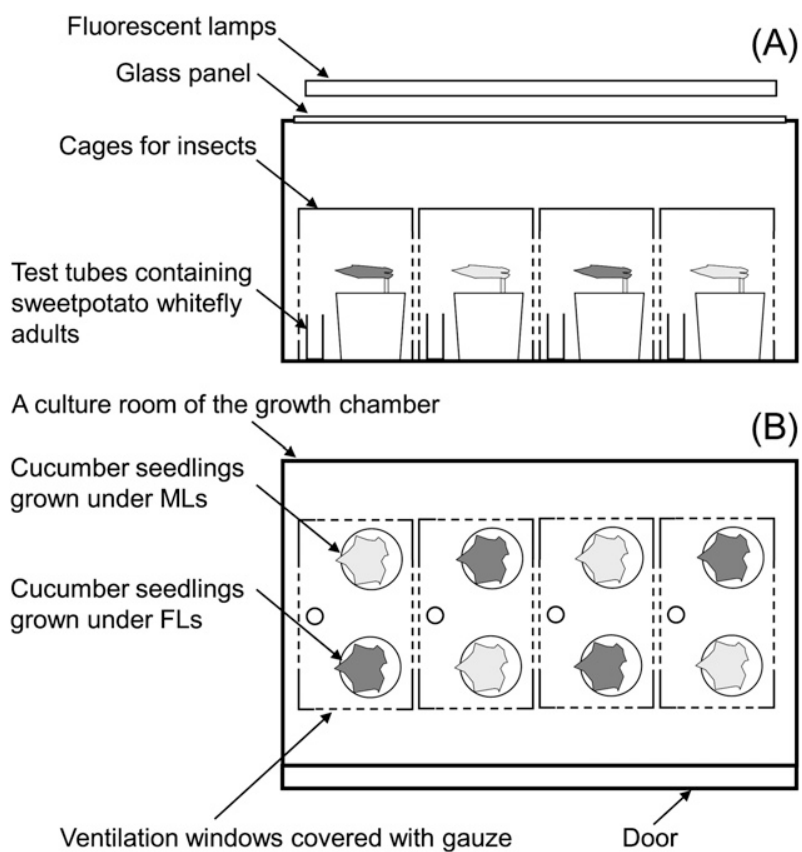

Fig. 2. Cross (A) and horizontal (B) section of experimental setup for the preference tests. Pairs of cucumber seedlings, one grown under fluorescent lamps (FLs) and the other under metal-halide lamps (MLs), were placed in cages and about 100 sweetpotato whitefly adults were released.

estimated as leaf area per leaf DW. The significance of differences between treatment means was determined by Student's $t$ test.

\section{Results and discussion}

The population of SPWF adults on the FL cucumber seedlings (36\%) was significantly smaller than that on the ML seedlings $[64 \%, P<0.001$ (Table 1)]. Thus, cucumber seedlings grown under FLs were less attractive than seedlings grown under MLs for the SPWF adults and, because the spectrum of ML was similar to that of natural light, would be less attractive than seedlings grown under natural light at the same PPF. This difference could occur in commercial transplant production because the daily PPF of the transplant production under artificial light can equal that of the transplant production under natural light (Kozai et al., 2006). A PPF of 350 
$\mu \mathrm{mol} \cdot \mathrm{m}^{-2} \cdot \mathrm{s}^{-1}$ is high enough for the production of transplants using artificial light.

The relative chlorophyll content of FL cucumber seedlings was 1.26 times that of ML seedlings (Table 2), indicated by a deeper color under FLs. The specific leaf area of FL cucumber seedlings was 0.91 time that of ML seedlings (Table 2 ). The smaller specific leaf area of FL cucumber seedlings indicates that the leaves of FL seedlings were thicker. The leaf color and thickness may partly explain the difference in population size, as in our previous study (Shibuya et al., 2009) in which cucumber seedlings grown under higher vapor pressure deficit had a deeper leaf color, thicker leaves, and consequent lower attractiveness to the SPWF adults. The leaf thickness could additionally deter the SPWF adults because the distance from the leaf surface to the vascular bundles was negatively correlated with SPWF adult density in another study (Chu et al., 1999). The difference in leaf color may also partially explain the difference in population size because SPWF adults respond to surface color as a cue to select landing site (Byrne and Bellows, 1991). The FL used in the preference tests had a strong peak at green/yellow color (wavelength of $\approx 550 \mathrm{~nm}$ ) to which greenhouse whitefly (Trialeurodes vaporariorum) adults are most sensitive (Coombe, 1982). Therefore, the preference tests under FLs were probably proper to examine response of the SPWF adults to surface color, whereas light source at the preference tests may possibly affect the behaviors of SPWF adults. Although the shoot length of FL cucumber seedlings was less than half that of ML seedlings (Table 2), we adjusted for this difference by replanting the seedlings to give the same distance from the growing-medium surface to the leaves. Thus, the difference in attractiveness between FL and ML cucumber seedlings seems to be due to morphologic responses of leaves to the different light qualities.

The R:FR values of the light source is probably the main cause of these morphologic response because the morphologic differences between FL and ML cucumber seedlings were similar to those between the cucumber seedlings grown under FLs with high (same as FL) and low (same as ML) R:FR ratio, in which only the FR irradiance was modified (Shibuya et al., 2010). The R:FR ratio under FLs (7.0) was much higher than that under solar radiation (1.2) and does not occur in natural environments.

Table 1. Proportion of sweetpotato whitefly (SPWF) adults on leaves of cucumber seedlings grown under fluorescent lamps (FLs) or metal-halide lamps (MLs) that provided a spectrum similar to that of natural light, $24 \mathrm{~h}$ after release in the preference tests.

\begin{tabular}{lcccc}
\hline \multirow{2}{*}{$\begin{array}{l}\text { Growing } \\
\text { condition }\end{array}$} & \multicolumn{2}{c}{ Proportion of SPWF adults $(\%)^{\mathrm{z}}$} & & $\begin{array}{c}\text { Mean } \pm \text { SE } \\
\text { of three trials (\%) }\end{array}$ \\
\cline { 2 - 4 } & Trial 1 & Trial 2 & Trial 3 & \\
\hline FLs & 40 & 39 & 29 & $36 \pm 4$ \\
MLs & 60 & 61 & 71 & $64 \pm 4$ \\
Significance $^{\mathrm{y}}$ & $P<0.001$ & $P<0.001$ & $P<0.001$ & $P<0.001$ \\
\hline
\end{tabular}

${ }^{2}$ Total population of SPWF adults in the four cages in Trials 1,2 , and 3 was 411,421 , and 373 , respectively. yThe significance of differences in the proportions of SPWF adults between treatments in each trial and their means were determined on the assumption of a normal distribution and the null hypothesis of a $50 \%$ split in proportions.

Table 2. Relative chlorophyll content, specific leaf area, and shoot length of cucumber seedlings grown under fluorescent lamps (FLs) or metal-halide lamps (MLs) that provided a spectrum similar to that of natural light $(n=10)$.

\begin{tabular}{lccc}
\hline $\begin{array}{l}\text { Growing } \\
\text { condition }\end{array}$ & $\begin{array}{c}\text { Relative } \\
\text { chlorophyll content } \\
{[\text { mean } \pm \mathrm{SE}]^{\mathrm{z}}}\end{array}$ & $\begin{array}{c}\text { Specific leaf area } \\
{[\text { mean } \pm \mathrm{SE}} \\
\left.\left(\mathrm{cm}^{2} \cdot \mathrm{g}^{-1} \mathrm{DW}\right)\right]^{\mathrm{y}}\end{array}$ & $\begin{array}{c}\text { Shoot length } \\
{[\mathrm{mean} \pm \mathrm{SE}} \\
(\mathrm{mm} / \mathrm{plant})]^{\mathrm{y}}\end{array}$ \\
\hline FLs & $40.1 \pm 1.3$ & $480 \pm 14$ & $31.3 \pm 1.0$ \\
MLs & $31.9 \pm 1.4$ & $526 \pm 23$ & $66.5 \pm 2.5$ \\
df & 18 & 18 & 18 \\
$t$ & 14.75 & 5.52 & 13.05 \\
$P^{\mathrm{x}}$ & $<0.001$ & $<0.001$ & $<0.001$ \\
\hline
\end{tabular}

${ }^{2}$ Chlorophyll meter value (SPAD-502).

${ }^{y} \mathrm{l} \mathrm{cm}^{2} \cdot \mathrm{g}^{-1}=4.3942$ inch $^{2} / \mathrm{oz}, \mathrm{l} \mathrm{mm}=0.0394$ inch.

'The significance of differences between treatment means was determined by Student's $t$ test.

With a lower R:FR ratio that occurs under natural light, shoot elongation and leaf expansion rates increase so that the plant can avoid shade, and chlorophyll content declines (Smith and Whitelam, 1997). As a consequence, plant leaves adapted to lower R:FR ratio tend to have lower resistance to herbivores (Izaguirre et al., 2006; McGuire and Agrawal, 2005; Moreno et al., 2009). On the other hand, lower attractiveness of FL cucumber seedlings is probably due to the inverse morphologic responses (i.e., increased leaf thickness and chlorophyll content and reduced shoot elongation) of the FL seedlings to those typical of shade avoidance, by the higher-than-natural R:FR ratio. Generally, low R:FR light is advantageous for improving the growth of plants because plants grow faster at low R:FR ratio (Murakami et al., 1991; Pausch et al., 1991; Shibuya et al., 2010), as we also observed in this study. On the other hand, the attractiveness of FL (higher R:FR ratio) cucumber seedlings to the SPWF adults was lower when compared with that of ML (lower R:FR ratio) seedlings, although the growth rate in the former was lower. There is, therefore, a trade-off between faster growth and reduced attractiveness to herbivores. This relationship is similar to the trade-off between shade avoidance and plant resistance to herbivores (McGuire and Agrawal, 2005; Moreno et al., 2009). There is a possibility that these plant responses and the consequent SPWF adults behaviors depend on plant variety because the plant responses to R:FR ratio vary depending on genotype (Moreno et al., 2009).

From these results, we conclude that the lower attractiveness of FL cucumber seedlings to SPWF adults was probably due to changes in leaf morphologic characteristics resulting from high R:FR light of FL. The plants with lower attractiveness are possibly more resistant to herbivores (Tansey et al., 2010). The fact that light quality affects the plant attractiveness to herbivores should be considered in selecting light sources for the transplant production under artificial light. In this study, we only carried out the choice preference test. The measurement of SPWF adult landing response in a no-choice situation would be necessary to evaluate the usefulness of this technology. In our previous study 
(Shibuya et al., 2009), a high vapor pressure deficit reduced the attractiveness of cucumber seedlings grown under FLs. Therefore, in applying these results to horticultural production, we must consider the interaction of environmental factors such as air moisture.

\section{Literature cited}

Ballaré, C. 2009. Illuminated behaviour: Phytochrome as a key regulator of light foraging and plant anti-herbivore defence. Plant Cell Environ. 32:713-725.

Berlinger, M.J. 1986. Host plant resistance to Bemisia tabaci. Agr. Ecosyst. Environ. 17:69-82.

Byrne, D.N. and T.S. Bellows, Jr. 1991. Whitefly biology. Annu. Rev. Entomol. $36: 431-457$.

Chu, C.C., A.C. Cohen, E.T. Natwick, G.S. Simmons, and T.J. Henneberry. 1999. Bemisia tabaci (Hemiptera: Aleyrodidae) biotype $\mathrm{B}$ colonisation and leaf morphology relationships in upland cotton cultivars. Austral. J. Entomol. 38:127-131.

Coombe, P.E. 1982. Visual behaviour of the greenhouse whitefly, Trialeurodesvaporariorum. Physiol. Entomol. 7:243-251.

Franklin, K.A. 2008. Shade avoidance. New Phytol. 179:930-944.

Izaguirre, M.M., C.A. Mazza, M. Biondini, I.T. Baldwin, and C.L. Ballaré. 2006. Remote sensing of future competitors: Impacts on plant defenses. Proc. Natl. Acad. Sci. USA 103:7170-7174.
Kozai, T. 2007. Propagation, grafting and transplant production in closed systems with artificial lighting for commercialization in Japan. Prop. Ornam. Plants 7: 145-149.

Kozai, T., K. Ohyama, and C. Chun. 2006. Commercialized closed systems with artificial lighting for plant production. Acta Hort. 711:61-70.

McAuslane, H.J. 1996. Influence of leaf pubescence on ovipositional preference of Bemisia argentifolii (Homoptera: Aleyrodidae) on soybean. Environ. Entomol. 25:834-841.

McGuire, R. and A.A. Agrawal. 2005. Trade-offs between the shade-avoidance response and plant resistance to herbivores? Tests with mutant Cucumis satious. Funct. Ecol. 19:1025-1031.

Moreno, J.E., Y. Tao, J. Chory, and C.L. Ballaré. 2009. Ecological modulation of plant defense via phytochrome control of jasmonate sensitivity. Proc. Natl. Acad. Sci. USA 106:4935-4940.

Murakami, K., K. Horaguchi, M. Morita, and I. Aiga. 1991. Growth control of the sunflower (Helianthus annums L. cv. Russian Mammoth) seedling by additional far-red irradiation (in Japanese with English summary and captions). Environ. Control Biol. 29:73-79.

Ohyama, K., K. Manabe, Y. Omura, C. Kubota, and T. Kozai. 2003. A comparison between closed-type and open-type transplant production systems with respect to quality of tomato plug transplants and resource consumption during summer (in Japanese with English summary and captions). Environ. Control Biol. 41: 57-61.

Pausch, R.C., S.J. Britz, and C.L. Mulchi. 1991. Growth and photosynthesis of soybean [Glycine $\max$ (L.) Merr.] in simulated vegetation shade: Influence of the ratio of red to far-red radiation. Plant Cell Environ. 14:647-656.

Shibuya, T., N. Hirai, Y. Sakamoto, and J. Komuro. 2009. Effects of morphological characteristics of Cucumis satious seedlings grown at different vapor pressure deficits on initial colonization of Bemisia tabaci (Hemiptera: Aleyrodidae). J. Econ. Entomol. 102:2265-2267.

Shibuya, T., R. Endo, N. Hayashi, Y. Kitamura, and Y. Kitaya. 2010. Potential photosynthetic advantages of cucumber (Cucumis sativus L.) seedlings grown under fluorescent lamps with high red:farred light. HortScience 45:553-558.

Smith, H. and G.C. Whitelam. 1997. The shade avoidance syndrome: Multiple responses mediated by multiple phytochromes. Plant Cell Environ. 20:840844.

Tansey, J.A., L.M. Dosdall, B.A. Keddie, and S.D. Noble. 2010. Contributions of visual cues to cabbage seedpod weevil, Ceutorhynchus obstrictus (Marsham) (Coleoptera: Curculionidae), resistance in novel host genotypes. Crop Protection 29: 476-481.

Waring, G.L. and N.S. Cobb. 1992. The impact of plant stress on herbivore population dynamics. Insect-Plant Interactions 4:167-226. 